\title{
Process Optimization and Wear Behavior of Red Mud Reinforced Aluminum Composites
}

\author{
Rajesh Shanmugavel, Thirumalai Kumaran Sundaresan, \\ Uthayakumar Marimuthu, and Pethuraj Manickaraj \\ Faculty of Mechanical Engineering, Kalasalingam University, Krishnankoil, Tamil Nadu 626 126, India \\ Correspondence should be addressed to Rajesh Shanmugavel; prinirajaki@yahoo.co.in
}

Received 29 October 2015; Accepted 6 January 2016

Academic Editor: Shyam Bahadur

Copyright (c) 2016 Rajesh Shanmugavel et al. This is an open access article distributed under the Creative Commons Attribution License, which permits unrestricted use, distribution, and reproduction in any medium, provided the original work is properly cited.

\begin{abstract}
This work presents the application of hybrid approach for optimizing the dry sliding wear behavior of red mud based aluminum metal matrix composites (MMCs). The essential input parameters are identified as applied load, sliding velocity, wt.\% of reinforcement, and hardness of the counterpart material, whereas the output responses are specific wear rate and Coefficient of Friction (COF). The Grey Relational Analysis (GRA) is performed to optimize the multiple performance characteristics simultaneously. The Principle Component Analysis (PCA) and entropy methods are applied to evaluate the values of weights corresponding to each output response. The experimental result shows that the wt.\% of reinforcements $(Q=34.9 \%)$ followed by the sliding velocity $(Q=34.5 \%)$ contributed more to affecting the dry sliding wear behavior. The optimized conditions are verified through the confirmation test, which exhibited an improvement in the grey relational grade of specific wear rate and COF by 0.3 and 0.034 , respectively.
\end{abstract}

\section{Introduction}

Aluminum MMCs created an interest to several industries, due to their high stiffness, specific strength, and superior wear resistance behavior, compared to unreinforced aluminum alloys. The superior mechanical and physical property leads to the use of these composites in automobile and engineering components where wear, tear, and seizure resistance are essential. Particulate MMCs are of special interest owing to the low cost of their raw materials and their ease of fabrication, making them suitable for applications requiring relatively high volume production. Among the different reinforcement materials, red mud is an emerging reinforcement because of its low cost and huge availability. Red mud emerged as the major waste material during the production of alumina from bauxite by Bayer's process. The estimated annual rate of production of red mud is nearly 30 million tons a year. The effective use of such waste material is essential in today's scenario.

For any industrial or commercial applications the wear behavior plays a major role in determining the product life.
However, the wear behaviors of red mud reinforced aluminum MMCs have not been examined by the researchers, which makes this work novel. Gopalakrishnan and Murugan [1] prepared Al-TiCp composite with different volume fraction of TiC, in an argon atmosphere by an enhanced stir casting method. They reported that the specific strength and the wear resistance of the composite were increased with higher $\%$ of $\mathrm{TiC}$ addition. Jo et al. [2] discussed the effect of SiC particle size on the wear properties of magnesium based hybrid metal matrix composites and suggested that the composite with large size $\mathrm{SiC}$ particles can improve the wear resistance compared with the smaller size particles. Alidokht et al. [3] incorporated $\mathrm{SiC}$ and $\mathrm{MoS}_{2}$ particles into the matrix of A356 $\mathrm{Al}$ alloy to form a hybrid composite. They showed that the $\mathrm{MoS}_{2}$ rich layer was on the top of the worn surface, which helped to decrease the plastic deformation in subsurface region and alleviated severe wear. Rao et al. [4] have prepared the wear mechanism map for aluminum matrix composite and observed that there are four wear regimes; they are ultramild wear, mild wear or oxidative wear, delamination wear, and severe wear. 
The GRA provides an efficient solution to the uncertainty, multi-input, and discrete data problem. In recent years, it has become a powerful tool for improving productivity during research and development, so that high quality products can be produced quickly and at low cost. Sahoo and Pal [5] used GRA as performance index to study the behavior of electroless Ni-P coating with respect to friction and wear characteristics. They reported that the interaction of load and time had significant influence on tribological performance. Siriyala et al. [6] investigated the dry sliding wear behavior of $\mathrm{SiC}$ reinforced aluminum composites produced using the molten metal mixing method. The optimization was performed using GRA and the results indicated that the sliding velocity was the most effective factor among the control parameters on dry sliding wear, followed by the reinforcement percentage, sliding distance, and contact stress. Soy et al. [7] studied the wear behaviors of A360 matrix reinforced with $\mathrm{SiC}$ and $\mathrm{B}_{4} \mathrm{C}$ ceramic particles using Taguchi method. They have concluded that the type of the material, applied load, and sliding speed exert a great effect on the specific wear rate, at $48.13 \%, 31.83 \%$, and $8.77 \%$, respectively.

In GRA, the grey relational grade is calculated by averaging the grey relational coefficient corresponding to each quality characteristic. However, the importance of each quality characteristic may be different. To overcome this problem, entropy measurement method is generally used for calculating the weighing factor of different quality characteristics. Apart from that, PCA is also used for determining the weighting values to calculate the grey relational grade. This study proposes GRA to optimize the dry sliding wear behavior of red mud reinforced aluminum composite. The work takes account of the correlation between the input parameters and the output quality characteristics. The corresponding weighting values of each parameter are determined by PCA and entropy method. The specific wear rate and COF are considered as the output quality parameters for the experiments. Finally, the worn surface morphology is observed using Scanning Electron Microscopic (SEM) image.

\section{Materials and Methods}

2.1. Composite Preparation. The powder metallurgy technique is adopted to fabricate the aluminum MMCs. The matrix material used in this study is aluminum powder with $99 \%$ purity with an average particle size of 150 to $300 \mu \mathrm{m}$. Red mud of angular shape is used as the reinforcement material $\left(\mathrm{Al}_{2} \mathrm{O}_{3}-16.8 \%, \mathrm{SiO}_{2}-15.2 \%, \mathrm{Na}_{2} \mathrm{O}_{3}-11.87 \%, \mathrm{Mn}-1.2 \%\right.$, $\mathrm{P}_{2} \mathrm{O}_{5}-0.67 \%, \mathrm{CaO}-2.45 \%, \mathrm{TiO}_{2}-3.7 \%, \mathrm{Fe}_{2} \mathrm{O}_{3}-33.8 \%$, and $\mathrm{Zn}-0.018 \%$ ) with an average particle size of 1.8 to $4 \mu \mathrm{m}$. The density of the aluminum and red mud is 2.7 and $3.2 \mathrm{~g} / \mathrm{cm}^{3}$, respectively.

The preprocessing is done with the ball mill and it is sieved to get uniform size of reinforcement material. The sieved red mud particle size is measured by Malvern laser particle size analyzer. The aluminum with various wt.\% of red mud particles $(3,4$, and $5 \mathrm{wt} . \%)$ is measured and mixed in the planetary ball mill for 2 hours at a constant speed of $150 \mathrm{rpm}$. The ball-to-powder ratio is maintained as $10: 1$ and liquid ethanol is used as the process control agent. The required number of samples is fabricated by applying a load of $300 \mathrm{kN}$, with a sintering temperature and sintering time as $600^{\circ} \mathrm{C}$ and $60 \mathrm{~min}$, respectively. The distribution of reinforcement in the composite is examined using SEM and is shown in Figures $1(\mathrm{a})-1(\mathrm{c})$.

2.2. Wear Test. The pin on disc apparatus is used to evaluate the specific wear rate and COF of the specimens. The specific wear rate is the wear volume divided by the product of the normal load and the sliding distance. COF is the ratio between the frictional force and the normal force [8]. The experimental facility is shown in Figure 2.

Tests are conducted under dry sliding conditions as per ASTM G99-95 (2010) at a room temperature of $27^{\circ} \mathrm{C}$ and relative humidity of 55\%. The applied load ranges from 10 to $50 \mathrm{~N}$ in steps of $20 \mathrm{~N}$, with sliding velocity of $2-4 \mathrm{~m} / \mathrm{s}$ in steps of $1 \mathrm{~m} / \mathrm{s}$ and constant sliding distance of $3000 \mathrm{~m}$. The pin (diameter $=10 \mathrm{~mm}$, length $=30 \mathrm{~mm}$ ) is initially cleaned with acetone and weighed using a digital electronic balance with a least count of $0.1 \mathrm{mg}$. EN32 steel with 58 and $60 \mathrm{HRC}$ and alumina oxide with $62 \mathrm{HRC}$ are used as the counterpart material (diameter $=200 \mathrm{~mm}$ ). The weight loss of the pin and the frictional force between the interfaces are measured.

2.3. Grey Relational Analysis. The following steps are to be carried out to optimize the multiperformance characteristics through GRA.

Step 1 (signal-to-noise $(S / N)$ ratio). In Taguchi method, the $S / N$ ratio is used to represent the performance characteristic and the largest value of $S / N$ ratio is required. The three types of $S / N$ ratio are lower-the-better, higher-the-better, and nominal-the-better [9]. The selected output responses such as specific wear rate and COF are lower-the-better characteristics which can be expressed as

$$
\eta_{i j}=-10 \log \left(\frac{1}{n} \sum_{j=1}^{n} y_{i j}^{2}\right),
$$

where $\eta_{i j}$ is the $j$ th $S / N$ ratio of the $i$ th experiment, $y_{i j}$ is the $i$ th experiment at the $j$ th test, and $n$ is the total number of the tests.

Step 2 (data preprocessing). Data preprocessing is the process of transferring the original sequence to a comparable sequence. For this purpose, the experimental results are normalized in the range between zero and one. The normalization for lower-the-better characteristics can be expressed as

$$
X_{i}^{0}(k)=\frac{\max X_{i}^{0}(k)-X_{i}^{0}(k)}{\max X_{i}^{0}(k)-\min X_{i}^{0}(k)},
$$

where $X_{i}^{0}(k)$ is the value after the grey relational generation (data preprocessing), $\max X_{i}^{0}(k)$ is the largest value of $X_{i}^{0}(k)$, $\min X_{i}^{0}(k)$ is the smallest value of $X_{i}^{0}(k)$, and $X^{0}$ is the desired value.

Step 3 (grey relational coefficient). The grey relational coefficient is calculated to express the relationship between the 


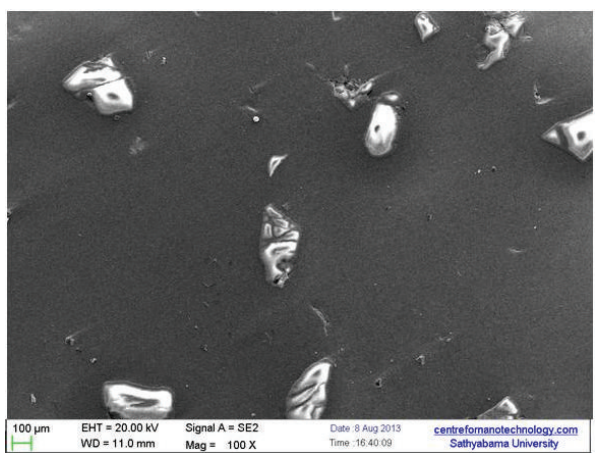

(a)

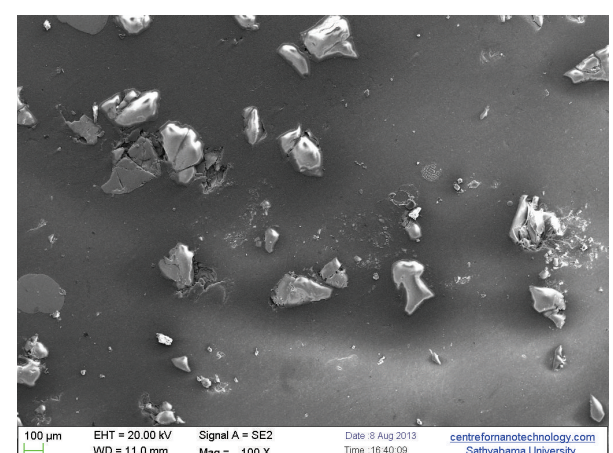

(b)

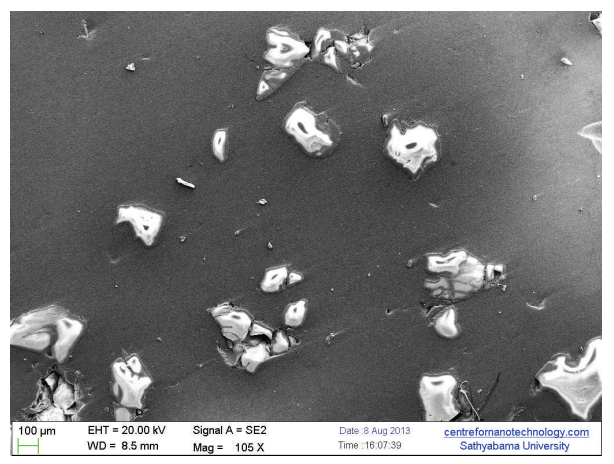

(c)

Figure 1: Dispersion of red mud (a) 3 wt.\%, (b) 4 wt.\%, and (c) 5 wt.\%.

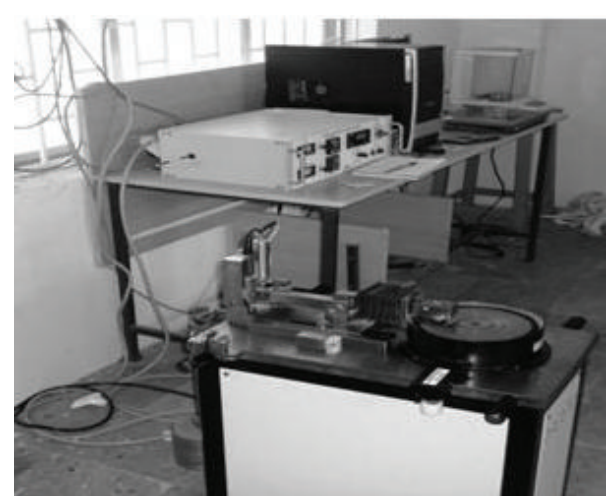

FIGURE 2: Experimental facility.

ideal and actual normalized experimental results. The grey relational coefficient can be expressed as

$$
\xi_{i}(k)=\frac{\Delta_{\min }+\varsigma \cdot \Delta_{\max }}{\Delta_{o i}(k)+\varsigma \cdot \Delta_{\max }},
$$

where $\xi_{i}(k)$ is the grey relational coefficient, $\Delta_{o i}(k)$ is the deviation sequence of the reference sequence $X_{0}(k)$ and the comparability sequence $X_{i}(k)$, namely

$$
\Delta_{o i}(k)=\left\|X_{0}(k)-X_{i}(k)\right\|,
$$

$$
\begin{aligned}
& \Delta_{\max }=\max _{\forall j \in i} \max _{\forall k}\left\|X_{0}(k)-X_{j}(k)\right\|, \\
& \Delta_{\min }=\min _{\forall j \in i} \min _{\forall k}\left\|X_{0}(k)-X_{j}(k)\right\|,
\end{aligned}
$$

and $\varsigma$ is distinguishing or identification coefficient: $\varsigma \epsilon$ $[0,1]=0.5$ is generally used.

Step 4 (grey relational grade). The average of the grey relational coefficient is calculated to obtain the grey relational grade. The grey relational grade is defined as

$$
\gamma_{i}=\sum_{k=1}^{n} w_{k} \xi_{i}(k),
$$

where $w_{k}$ represents the normalized weighting value of factor $k$. In GRA, the grey relational grade is used to show the relationship among the sequences. If two sequences are identical, then the value of grey relational grade is equal to $1[10]$. The grey relational grade also indicates the degree of influence that the comparability sequence could exert over the reference sequence. Therefore, if a particular comparability sequence is more important than the other comparability sequence to the reference sequence, then the grey relational grade for that comparability sequence and reference sequence will be higher than other grey relational grades. In this study the weighting value $\left(w_{k}\right)$ is obtained from the principal component analysis and by entropy method. 
TABLE 1: Experimental layout and results.

\begin{tabular}{|c|c|c|c|c|c|c|}
\hline S. number & $\begin{array}{l}\text { Load } \\
(\mathrm{N})\end{array}$ & $\begin{array}{l}\text { Sliding velocity } \\
(\mathrm{m} / \mathrm{s})\end{array}$ & wt.\% of red mud & $\begin{array}{c}\text { Counterpart hardness } \\
\text { (HRC) }\end{array}$ & $\begin{array}{c}\text { Specific wear } \\
\left(\times 10^{-13} \mathrm{~mm}^{3} / \mathrm{Nm}\right)\end{array}$ & COF \\
\hline 1 & 10 & 2 & 3 & 58 & 3.3659 & 0.489 \\
\hline 2 & 10 & 2 & 4 & 60 & 6.269 & 0.365 \\
\hline 3 & 10 & 2 & 5 & 62 & 8.2369 & 0.276 \\
\hline 4 & 10 & 3 & 3 & 60 & 7.9945 & 0.578 \\
\hline 5 & 10 & 3 & 4 & 62 & 13.2156 & 0.385 \\
\hline 6 & 10 & 3 & 5 & 58 & 15.2389 & 0.356 \\
\hline 7 & 10 & 4 & 3 & 62 & 4.269 & 0.312 \\
\hline 8 & 10 & 4 & 4 & 58 & 13.567 & 0.392 \\
\hline 9 & 10 & 4 & 5 & 60 & 11.289 & 0.295 \\
\hline 10 & 30 & 2 & 3 & 58 & 1.239 & 0.631 \\
\hline 11 & 30 & 2 & 4 & 60 & 1.56 & 0.615 \\
\hline 12 & 30 & 2 & 5 & 62 & 5.5216 & 0.315 \\
\hline 13 & 30 & 3 & 3 & 60 & 1.1236 & 0.685 \\
\hline 14 & 30 & 3 & 4 & 62 & 15.259 & 0.4 \\
\hline 15 & 30 & 3 & 5 & 58 & 10.5698 & 0.562 \\
\hline 16 & 30 & 4 & 3 & 62 & 7.369 & 0.416 \\
\hline 17 & 30 & 4 & 4 & 58 & 8.369 & 0.525 \\
\hline 18 & 30 & 4 & 5 & 60 & 5.239 & 0.386 \\
\hline 19 & 50 & 2 & 3 & 58 & 0.1139 & 0.656 \\
\hline 20 & 50 & 2 & 4 & 60 & 0.2149 & 0.6 \\
\hline 21 & 50 & 2 & 5 & 62 & 10.1157 & 0.395 \\
\hline 22 & 50 & 3 & 3 & 60 & 0.9926 & 0.615 \\
\hline 23 & 50 & 3 & 4 & 62 & 10.2569 & 0.462 \\
\hline 24 & 50 & 3 & 5 & 58 & 13.697 & 0.401 \\
\hline 25 & 50 & 4 & 3 & 62 & 3.269 & 0.425 \\
\hline 26 & 50 & 4 & 4 & 58 & 11.239 & 0.385 \\
\hline 27 & 50 & 4 & 5 & 60 & 5.369 & 0.351 \\
\hline
\end{tabular}

2.4. Principal Component Analysis and Entropy Method. PCA approach explains the structure of variance-covariance by way of the linear combinations of each performance characteristic. It is a statistical method which uses an orthogonal transformation to convert the correlated variables into linearly uncorrelated variables called principal components [11]. The total number of principal components will be less than or equal to the number of original variables. The first principal component has the largest possible variance and each subsequent component has the highest variance with a constraint that it is orthogonal to the preceding components. The uncorrelated principal component is formulated as

$$
Y_{m k}=\sum_{i=1}^{n} X_{m}(i) \cdot V_{i k},
$$

where $Y_{m 1}$ is the first principal component and $Y_{m 2}$ is the second principal component and so on. The principal components are aligned in descending order with respect to variance, and therefore the first principal component $Y_{m 1}$ accounts for most variance in the data.

Entropy is a measure of irregularity of states such as imbalance and uncertainty. As applying the concept to the weight measurement, an attribute with a large entropy means it has a great diversity of responses. Thus the attribute has more significant influence on the response. The entropy is a mapping function $f_{i}:[0,1] \rightarrow[0,1]$ used to satisfy all these conditions: $f_{i}(0)=0$ and $f_{i}(x)=f_{i}(1-x)$ and $f_{i}(x)$ is monotonic increasing in the range $x \in(0,0.5)$. Thus, $w_{e}(x)$ can be used as the mapping function in entropy measure, where $w_{e}(x)=$ $x e^{(1-x)}+(1-x) e^{x}-1$. The maximum value of function occurs at $x=0$ and the value of $e^{0.5}-1=0.6478$.

Initially, the normalized coefficient, entropy of each quality characteristic $\left(e_{j}\right)$, and the total sum of entropy $(E)$ are calculated. Then the weight of each quality characteristic is calculated as

$$
w_{j}=\frac{1 / p-E\left[1-e_{j}\right]}{\sum_{j=1}^{p} 1 / p-E\left[1-e_{j}\right]}, \quad j=1, \ldots, p .
$$

\section{Result and Discussion}

3.1. Plan of Experiments and Analysis of Results. The number of experiments is selected based on the number of factors and its levels. The most influencing factors such as applied load and sliding velocity and wt.\% of red mud and counterpart hardness are considered. In this study, the specific wear rate 
TABLE 2: Grey relational analysis.

\begin{tabular}{|c|c|c|c|c|c|c|c|c|}
\hline \multirow{2}{*}{ S. number } & \multicolumn{2}{|c|}{$S / N$ ratio $(\mathrm{dB})$} & \multicolumn{2}{|c|}{ Data preprocessing } & \multicolumn{2}{|c|}{ Grey relational coefficient } & \multirow{2}{*}{ Grey relational grade } & \multirow{2}{*}{ Ordeı } \\
\hline & Specific wear rate & $\mathrm{COF}$ & Specific wear rate & $\mathrm{COF}$ & Specific wear rate & $\mathrm{COF}$ & & \\
\hline 1 & -10.542 & 6.213823 & 0.50627 & 0.62920 & 0.660332 & 0.063161 & 0.723493 & 20 \\
\hline 2 & -15.944 & 8.754143 & 0.612864 & 0.30747 & 0.736494 & 0.04612 & 0.782614 & 15 \\
\hline 3 & -18.3153 & 11.18182 & 0.659657 & 0 & 0.775772 & 0.036667 & 0.812439 & 13 \\
\hline 4 & -18.0558 & 4.761443 & 0.654537 & 0.81315 & 0.771272 & 0.080076 & 0.851348 & 11 \\
\hline 5 & -22.4217 & 8.290785 & 0.740688 & 0.36615 & 0.854708 & 0.048508 & 0.903216 & 5 \\
\hline 6 & -23.6591 & 8.971 & 0.765104 & 0.28000 & 0.881742 & 0.045082 & 0.926824 & 2 \\
\hline 7 & -12.6065 & 10.11691 & 0.547008 & 0.13487 & 0.687503 & 0.040289 & 0.727792 & 19 \\
\hline 8 & -22.6497 & 8.134279 & 0.745186 & 0.38597 & 0.859563 & 0.049371 & 0.908934 & 4 \\
\hline 9 & -21.0531 & 10.60356 & 0.713681 & 0.07323 & 0.826674 & 0.038549 & 0.865222 & 9 \\
\hline 10 & -1.86143 & 3.999413 & 0.334979 & 0.90966 & 0.566237 & 0.093168 & 0.659405 & 24 \\
\hline 11 & -3.86249 & 4.222498 & 0.374465 & 0.88141 & 0.585469 & 0.088912 & 0.674381 & 22 \\
\hline 12 & -14.8413 & 10.03379 & 0.591106 & 0.14540 & 0.719553 & 0.040602 & 0.760156 & 18 \\
\hline 13 & -1.01223 & 3.286189 & 0.318222 & 1 & 0.558452 & 0.11 & 0.668452 & 23 \\
\hline 14 & -23.6705 & 7.9588 & 0.76533 & 0.40820 & 0.882 & 0.050376 & 0.932376 & 1 \\
\hline 15 & -20.4813 & 5.005274 & 0.702399 & 0.78227 & 0.815499 & 0.076631 & 0.89213 & 6 \\
\hline 16 & -17.3482 & 7.618133 & 0.640573 & 0.45134 & 0.759258 & 0.052448 & 0.811706 & 14 \\
\hline 17 & -18.4535 & 5.596814 & 0.662384 & 0.70735 & 0.778191 & 0.069388 & 0.847578 & 12 \\
\hline 18 & -14.385 & 8.268254 & 0.582101 & 0.36901 & 0.712768 & 0.04863 & 0.761398 & 16 \\
\hline 19 & 18.86953 & 3.661923 & -0.0741 & 0.95241 & 0.422467 & 0.100441 & 0.522908 & 27 \\
\hline 20 & 13.35527 & 4.436975 & 0.034713 & 0.85425 & 0.453065 & 0.085172 & 0.538238 & 26 \\
\hline 21 & -20.0999 & 8.068058 & 0.694872 & 0.39436 & 0.808211 & 0.049745 & 0.857956 & 10 \\
\hline 22 & 0.063815 & 4.222498 & 0.296989 & 0.88141 & 0.54889 & 0.088912 & 0.637802 & 25 \\
\hline 23 & -20.2203 & 6.70716 & 0.697248 & 0.56672 & 0.810497 & 0.058932 & 0.86943 & 8 \\
\hline 24 & -22.7325 & 7.937113 & 0.74682 & 0.41095 & 0.861341 & 0.050503 & 0.911844 & 3 \\
\hline 25 & -10.2883 & 7.432221 & 0.501263 & 0.47489 & 0.65714 & 0.053653 & 0.710793 & 21 \\
\hline 26 & -21.0146 & 8.290785 & 0.71292 & 0.36615 & 0.82591 & 0.048508 & 0.874418 & 7 \\
\hline 27 & -14.5979 & 9.093858 & 0.586302 & 0.26444 & 0.715918 & 0.044514 & 0.760432 & 17 \\
\hline
\end{tabular}

TABLE 3: Response table for grey relational grade.

\begin{tabular}{|c|c|c|c|c|c|}
\hline \multirow{2}{*}{ Symbol } & \multirow{2}{*}{ Parameters } & \multicolumn{3}{|c|}{ Average grey relational grade } & \multirow{2}{*}{ Max-Min } \\
\hline & & Level 1 & Level 2 & Level 3 & \\
\hline A & Applied load & 0.8335 & 0.7786 & 0.7426 & 0.0190 \\
\hline B & Sliding velocity & 0.7035 & 0.8437 & 0.8075 & 0.0168 \\
\hline $\mathrm{C}$ & wt.\% of red mud & 0.7015 & 0.8145 & 0.8387 & 0.0373 \\
\hline $\mathrm{D}$ & Counterpart material hardness & 0.8075 & 0.7266 & 0.8206 & 0.0297 \\
\hline
\end{tabular}

and COF are selected as performance characteristic. As there are four factors and each is at three levels, L27 orthogonal array is chosen for conducting the experiments. The layout as per L27 array and the experimental results are shown in Table 1.

The $S / N$ ratio, data preprocessing, and the grey relational coefficient for both quality characteristics of each deviation sequence are calculated. Grey relational coefficient is used to evaluate the correlation coefficient matrix and corresponding Eigenvalues. Square of the Eigenvalue matrix represents the contribution of the respective performance characteristics to the principle component. The calculated values of weights for specific wear rate and COF are 0.882 and 0.110 , respectively, which is found by entropy method. The calculated weighting values are taken for further analysis, since PCA method has given equal importance to the quality characteristics, whereas entropy method reflects relative importance to the quality characteristics. The obtained weights of each quality characteristic are further used to calculate the grey relational grade. Table 2 shows the performed GRA for the dry sliding wear behavior of the prepared composites.

The main effects of each input process parameter on grey relational grade are shown in Table 3. The optimum input parameter level based on maximum average grey relational grade is found as A1 B2 C3 D3, that is, applied load at $10 \mathrm{~N}$, sliding velocity at $3 \mathrm{~m} / \mathrm{s}, 5 \mathrm{wt} . \%$ of red mud, and counterpart material hardness at $62 \mathrm{HRC}$. 
TABLE 4: Result of ANOVA.

\begin{tabular}{lccccc}
\hline Symbol & Degree of freedom & Sum of squares & Mean sum of squares & $F$-test & Contribution $(Q)$ \\
\hline A & 2 & 0.037718 & 0.018859 & 5.12 & 13.6 \\
B & 2 & 0.095382 & 0.047691 & 12.95 & 13.11 \\
C & 2 & 0.096554 & 0.048277 & 6.33 & 34.5 \\
D & 2 & 0.046632 & 0.023317 & 16.87 \\
Error & 18 & 0.066303 & 0.003684 & 0.13 \\
Total & 26 & 0.342592 & & 100 \\
\hline
\end{tabular}

The difference between the maximum and minimum value of the grey relational grade during dry sliding wear is reported as follows: 0.0190 for applied load, 0.0168 for sliding velocity, 0.0373 for wt. $\%$ of red mud, and 0.0297 for counterpart material hardness. The most effective parameter affecting the multiple performance characteristics is determined by finding the greatest value among the parameters. The result indicates that the wt.\% of red mud has the strongest effect on the output response during dry sliding wear test.

3.2. Analysis of Variance (ANOVA). The results of ANOVA for the grey relational grades are given in Table 4 . The contribution of each parameter which affects the multiperformance characteristics is wt.\% of the red mud $(Q=34.9 \%)$, sliding velocity $(Q=34.5 \%)$, counterpart material hardness $(Q=$ $16.87 \%)$, and applied load $(Q=13.6 \%)$. Thus, it is found that the dry sliding wear performance is strongly affected by the wt.\% of red mud and the sliding velocity. The F-test is also performed to find the physical significance of each input parameter on the output response [12]. It is found that, at $95 \%$ of confidence interval, $F_{\text {Calculated }}>F_{0.05,2,18}=3.55$. Hence, all the input process parameters showed significance on affecting the dry sliding wear behavior.

3.3. Confirmation Experiment. Once the optimal levels of the input parameters are selected, the final step is to verify the improvement of the output response. The estimated grey relational grade $\tau_{e}$ using the optimal level of input parameters can be calculated as

$$
\tau_{e}=\tau_{m}+\sum_{i=1}^{p}\left[\tau_{i}-\tau_{m}\right],
$$

where $\tau_{m}$ is total mean of grey relational grade, $\tau_{i}$ is mean of grey relational grade at the optimal level, and $p$ is number of input parameters that significantly affect the multiple performance characteristics. The results of confirmation experiments are shown in Table 5, and it is found that specific wear rate is decreased from 3.365 to 3.065 and COF is decreased from 0.365 to 0.331 .

3.4. Surface Morphology. The worn surface of the composite with 3 wt. $\%$ of red mud is shown in Figure 3(a). Severe abrasion is predominant with wear debris particles scattered on the mating surface. The wear tracks are still visible with some minute flaw. The minimum applied load and sliding velocity
TABLE 5: Confirmation experiment.

\begin{tabular}{lccc}
\hline & \multirow{2}{*}{ Initial parameter } & \multicolumn{2}{c}{ Optimal parameters } \\
& & Prediction & Experiment \\
\hline Level & A1 B1 C1 D1 & A1 B2 C3 D3 & A1 B2 C3 D3 \\
Specific wear rate & 3.365 & 2.983 & 3.065 \\
COF & 0.365 & 0.325 & 0.331 \\
\hline
\end{tabular}

avoided the surface from adhesion and plastic deformation. Figure 3(b) shows the formation of micro cut and grooves on the composite with $4 \mathrm{wt}$. $\%$ of red mud. The formation of lay is also visible throughout the surface. However, mild abrasion is evident when the red mud wt.\% is further increased (Figure 3(c)). The red mud particles resisted the wear by increasing the interfacial bond with the matrix. Thus, fewer defects are noticed on the surface of the composite with $5 \mathrm{wt}$ \% red mud even at higher load and sliding velocity conditions.

\section{Conclusions}

The grey based entropy method is used to optimize the multiresponse characteristic of dry sliding wear behavior of red mud reinforced aluminum MMCs and the following observations are made:

(i) The composite is successfully prepared through the powder metallurgy technique and the dispersion of the red mud particles in the matrix is ensured with the SEM image.

(ii) The optimum levels of input parameters are found by GRA as applied load at $10 \mathrm{~N}$, sliding velocity at $3 \mathrm{~m} / \mathrm{s}$, $5 \mathrm{wt} . \%$ of red mud, and counterpart material hardness at $62 \mathrm{HRC}$.

(iii) The results of ANOVA show that the wt.\% of the red mud particles in the composite and the sliding velocity contributed more to affecting the wear behavior.

(iv) The higher wt.\% of red mud increases the wear resistance property of the composite.

(v) The morphological changes on the worn surface of the samples are examined through SEM. For all the trials it is observed that, mild-to-severe wear exists but the seizure condition was not noticed. 


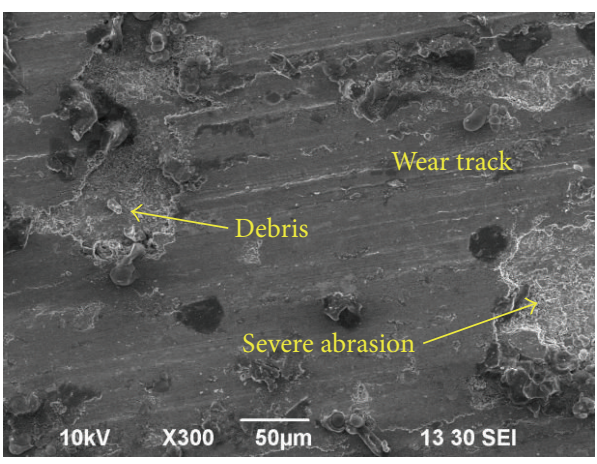

(a)

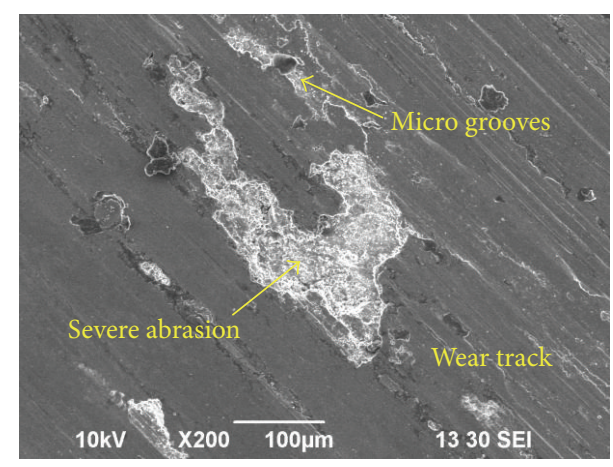

(b)

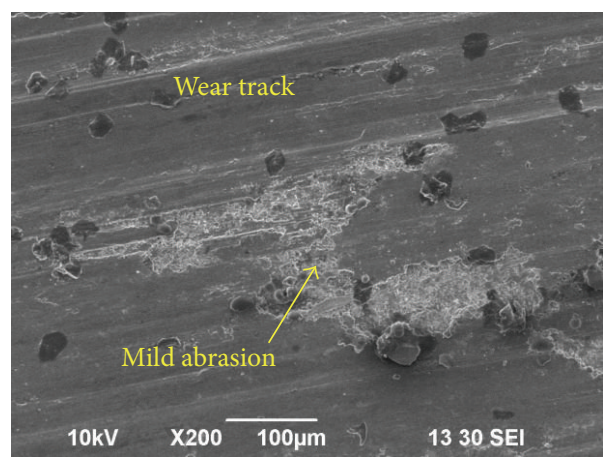

(c)

Figure 3: Worn surface: (a) A1 B2 C1 D1, (b) A1 B2 C2 D2, and (c) A1 B2 C3 D3.

\section{Conflict of Interests}

The authors declare that there is no conflict of interests regarding the publication of this paper.

\section{References}

[1] S. Gopalakrishnan and N. Murugan, "Production and wear characterisation of AA 6061 matrix titanium carbide particulate reinforced composite by enhanced stir casting method," Composites Part B: Engineering, vol. 43, no. 2, pp. 302-308, 2012.

[2] S. K. Jo, W. J. Lee, Y. H. Park, and I. M. Park, "Effect of SiC particle size on wear properties of $\mathrm{Al}_{2} \mathrm{O}_{3} \cdot \mathrm{SiO}_{2} / \mathrm{SiC} / \mathrm{Mg}$ hybrid metal matrix composites," Tribology Letters, vol. 45, no. 1, pp. 101-107, 2012.

[3] S. A. Alidokht, A. Abdollah-Zadeh, and H. Assadi, "Effect of applied load on the dry sliding wear behaviour and the subsurface deformation on hybrid metal matrix composite," Wear, vol. 305, no. 1-2, pp. 291-298, 2013.

[4] R. N. Rao, S. Das, D. P. Mondal, G. Dixit, and S. L. T. Devi, “Dry sliding wear maps for AA7010 (Al- $\mathrm{Zn}-\mathrm{Mg}-\mathrm{Cu}$ ) aluminium matrix composite," Tribology International, vol. 60, pp. 77-82, 2013.

[5] P. Sahoo and S. K. Pal, "Tribological performance optimization of electroless Ni-P coatings using the Taguchi method and grey relational analysis," Tribology Letters, vol. 28, no. 2, pp. 191-201, 2007.

[6] R. Siriyala, G. K. Alluru, R. M. R. Penmetsa, and M. Duraiselvam, "Application of grey-taguchi method for optimization of dry sliding wear properties of aluminum MMCs," Frontiers of Mechanical Engineering, vol. 7, no. 3, pp. 279-287, 2012.

[7] U. Soy, F. Ficici, and A. Demir, "Evaluation of the Taguchi method for wear behavior of $\mathrm{Al} / \mathrm{SiC} / \mathrm{B}_{4} \mathrm{C}$ composites," Journal of Composite Materials, vol. 46, no. 7, pp. 851-859, 2012.

[8] S. T. Kumaran and M. Uthayakumar, "Investigation on the dry sliding friction and wear behavior of AA6351-SiC- $\mathrm{B}_{4} \mathrm{C}$ hybrid metal matrix composites," Proceedings of the Institution of Mechanical Engineers Part J: Journal of Engineering Tribology, vol. 228, no. 3, pp. 332-338, 2014.

[9] S. Thirumalai Kumaran, M. Uthayakumar, and S. Aravindan, "Analysis of dry sliding friction and wear behaviour of AA6351$\mathrm{SiC}-\mathrm{B}_{4} \mathrm{C}$ composites using grey relational analysis," TribologyMaterials, Surfaces and Interfaces, vol. 8, no. 4, pp. 187-193, 2014.

[10] S. Thirumalai Kumaran, M. Uthayakumar, A. Slota, and J. Zajac, "Application of grey relational analysis in high speed machining of $\mathrm{AA}(6351)-\mathrm{SiC}-\mathrm{B}_{4} \mathrm{C}$ hybrid composite," International Journal of Materials and Product Technology, vol. 51, no. 1, pp. 17-31, 2015.

[11] Y.-M. Chiang and H.-H. Hsieh, "The use of the Taguchi method with grey relational analysis to optimize the thin-film sputtering process with multiple quality characteristic in color filter manufacturing," Computers and Industrial Engineering, vol. 56, no. 2, pp. 648-661, 2009.

[12] S. Thirumalai Kumaran, M. Uthayakumar, S. Aravindan, and S. Rajesh, "Dry sliding wear behavior of $\mathrm{SiC}$ and $\mathrm{B}_{4} \mathrm{C}$-reinforced AA6351 metal matrix composite produced by stir casting process," Proceedings of the Institution of Mechanical Engineers L: Journal of Materials: Design and Applications, 2015. 


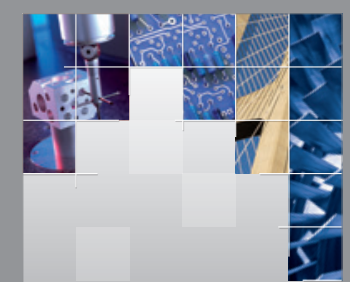

\section{Enfincering}
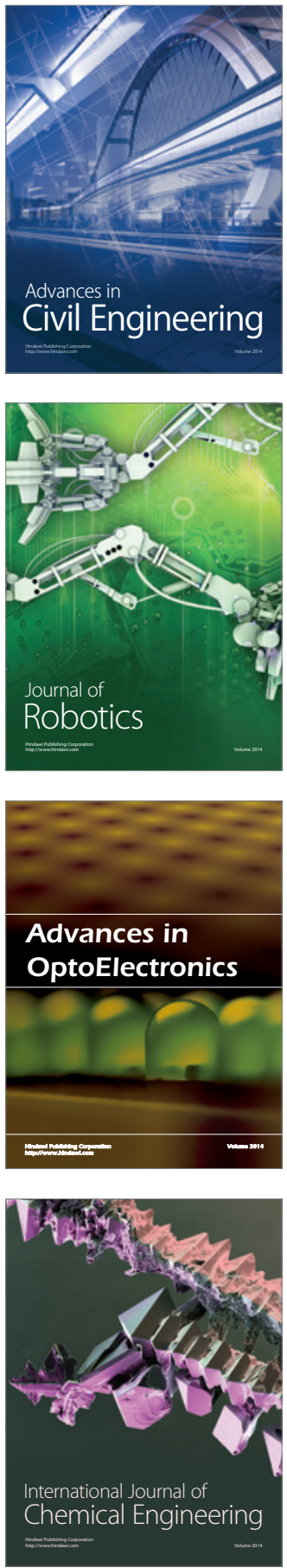

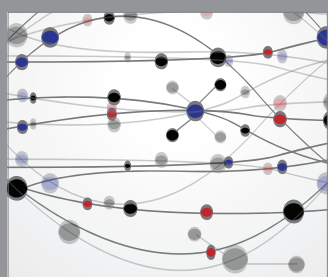

The Scientific World Journal

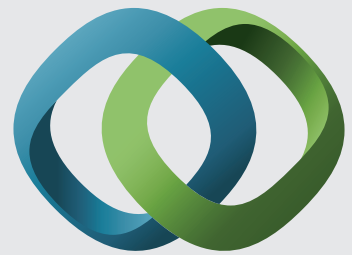

\section{Hindawi}

Submit your manuscripts at

http://www.hindawi.com
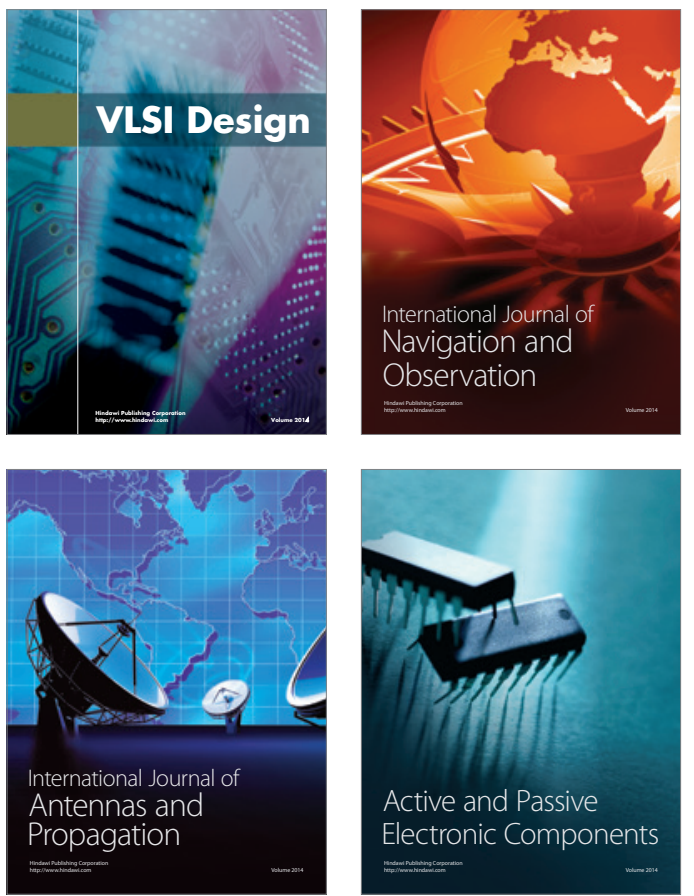
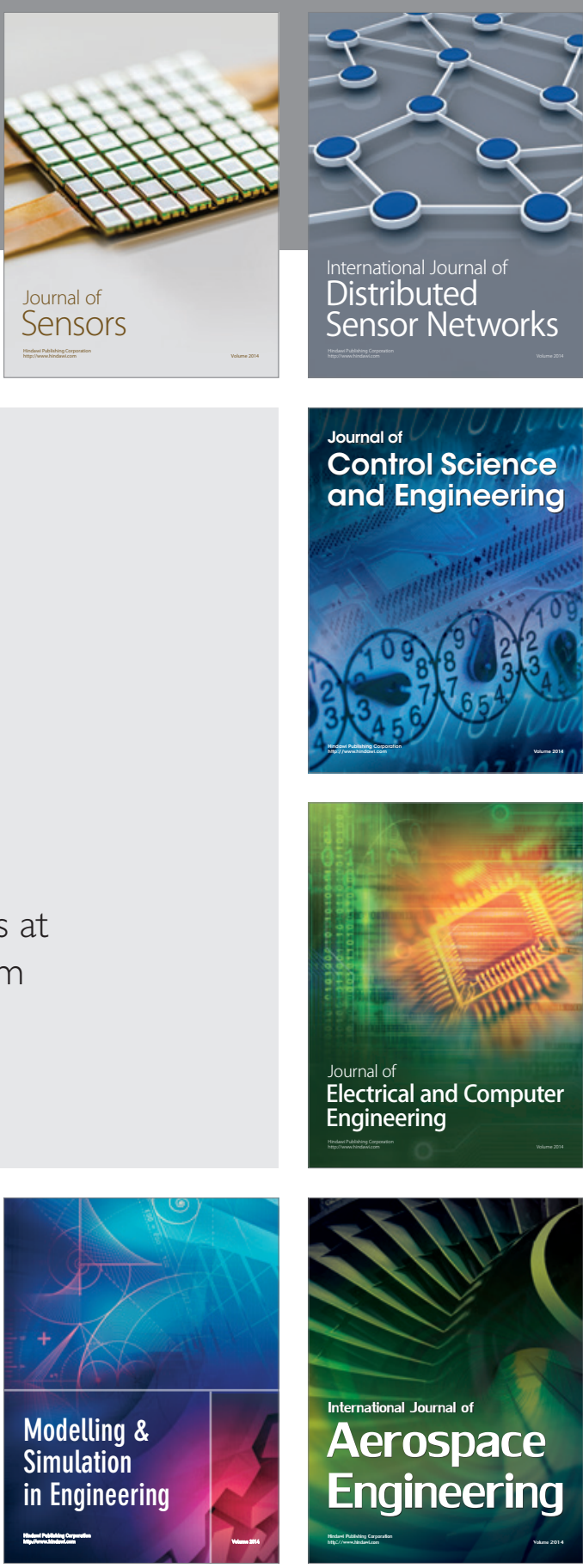

International Journal of

Distributed

Sensor Networks

Journal of

Control Science

and Engineering
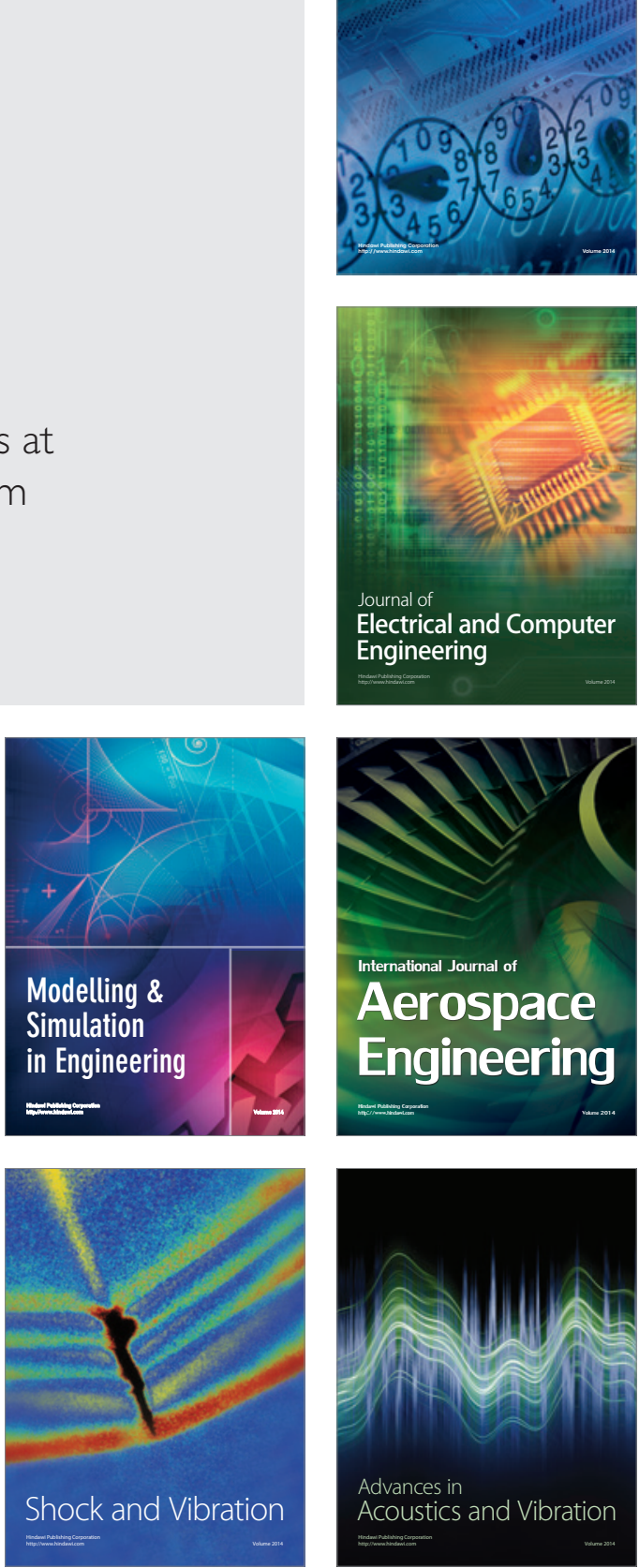